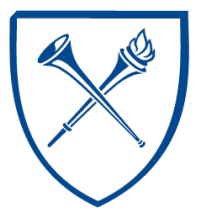

\title{
Reducing diarrhea through the use of household-based ceramic water filters: a randomized, controlled trial in rural Bolivia
}

Thomas Clasen, Emory University

Joseph Brown, University of North Carolina

Simon Collin, First Water

Oscar Suntura

Sandy Cairncross, London School of Hygiene and Tropical Medicine

Journal Title: American Journal of Tropical Medicine and Hygiene Volume: Volume 70, Number 6

Publisher: American Society of Tropical Medicine and Hygiene | 2004-06,

Pages 651-657

Type of Work: Article | Final Publisher PDF

Permanent URL: http://pid.emory.edu/ark:/25593/f92km

Final published version: http://www.ajtmh.org/content/70/6/651.long

\section{Copyright information:}

(C) 2004 The American Society of Tropical Medicine 


\title{
REDUCING DIARRHEA THROUGH THE USE OF HOUSEHOLD-BASED CERAMIC WATER FILTERS: A RANDOMIZED, CONTROLLED TRIAL IN RURAL BOLIVIA
}

\author{
THOMAS F. CLASEN, JOSEPH BROWN, SIMON COLLIN, OSCAR SUNTURA, AND SANDY CAIRNCROSS \\ Department of Infectious and Tropical Diseases, London School of Hygiene and Tropical Medicine, London, United Kingdom; \\ Department of Environmental Sciences and Engineering, University of North Carolina, Chapel Hill, North Carolina; First Water, \\ Ltd., Bristol, United Kingdom; Fundación Sumaj Huasi, La Paz, Bolivia
}

\begin{abstract}
Ceramic water filters have been identified as one of the most promising and accessible technologies for treating water at the household level. In a six-month trial, water filters were distributed randomly to half of the 50 participating households in a rural community in Bolivia; the remaining households continued to use customary water handling practices and served as controls. In four rounds of sampling following distribution of the filters, $100 \%$ of the 96 water samples from the filter households were free of thermotolerant coliforms compared with $15.5 \%$ of the control household samples. Diarrheal disease risk for individuals in intervention households was $70 \%$ lower than for controls $(95 \%$ confidence interval $[\mathrm{CI}]=53-80 \% ; P<0.001)$. For children less than five years old, the reduction in risk was $83 \%$ (95\% CI $=51-94 \% ; P<0.001)$. These results show that affordable ceramic water filters enable low-income households to treat and maintain the microbiologic quality of their drinking water.
\end{abstract}

\section{INTRODUCTION}

Contaminated drinking water, along with inadequate supplies of water for personal hygiene and poor sanitation, are the main contributors to an estimated four billion cases of diarrhea each year, causing 2.5 million deaths. ${ }^{1}$ Among children under less than five years old in developing countries, diarrheal disease accounts for $21 \%$ of all deaths. ${ }^{2}$ In Bolivia, diarrheal disease is the largest cause of morbidity and mortality among children less than five years old, with an estimated 500,000 cases and 7,900 deaths, and a prevalence of $30 \% .^{3}$ By inhibiting normal consumption of foods and adsorption of nutrients, diarrheal diseases are also an important cause of malnutrition, leading to impaired physical growth and cognitive development, ${ }^{4}$ reduced resistance to infection, ${ }^{5}$ and potentially long-term gastrointestinal disorders. ${ }^{6}$

Bolivia has made significant progress in bringing access to safe water to its marginalized regions. Nevertheless, an estimated $45 \%$ still lack such access in rural areas, ranking among the highest in the hemisphere. ${ }^{7}$ While the delivery of safe and reliable water services is an essential goal, a World Health Organization (WHO)-sponsored literature review of existing research concluded that simple, acceptable, low-cost interventions at the household and community level are capable of dramatically improving the microbial quality of household stored water and reducing risks of diarrheal disease and death. ${ }^{8}$ Among the alternatives that the review deems most promising is ceramic microfiltration.

Ceramic filters are manufactured in a variety of pore sizes. Good-quality filters have micron or submicron ratings and are impregnated or coated with silver for additional bacteriostatis. The filters are typically formed into hollow cylindrical "candles" that are mounted into the top of a two-compartment vessel. Pathogens are removed as contaminated water passes through the candles in the top compartment to the lower holding compartment. The filtered water can only be accessed from this lower compartment by a tap or spigot, thus protecting it from the risk of recontamination prior to consumption. ${ }^{9}$

In an effort to evaluate ceramic drip filters as a health intervention in developing countries, the investigators, in collaboration with the Pan American Health Organization, undertook a six-month intervention study in a rural community near Cochabamba, Bolivia. The outcome parameters of this study include microbiologic effectiveness, diarrhea prevention, cost-effectiveness, acceptability, and willingness-to-pay. This report presents the results on microbiologic effectiveness and diarrhea prevention.

\section{MATERIALS AND METHODS}

Study site. Charinco is a rural community of approximately 360 people located $20 \mathrm{~km}$ west of Cochabamba, Bolivia in the Municipality of Vinto. The community consists of 80-90 households dispersed among small agricultural plots. It was selected as the study site based on its reliance upon surface water for drinking and its practice of storing such water in the home. After meeting with community representatives and performing an initial analysis of water samples, 50 households were recruited to participate in the study. Investigators explained that half of the participating households would receive a filter at the inception of the study, and the other half six months later. An investigator then collected baseline information from the head of each participating household of each by means of a standard questionnaire, and obtained a sample of the pre-intervention drinking water for baseline data purposes. Thereafter, households were randomly allocated by lottery, half to an intervention group and half to a control group.

Intervention. Intervention group households received a gravity water filter system. It consisted of two locally produced, 15-liter, covered, clear plastic buckets, two Katadyn ${ }^{\circledR}$ 240-mm porous ceramic filter elements (Katadyn Produkte AG, Zurich, Switzerland), and a metal valve for dispensing the product water (Figure 1). The Katadyn Ceradyn ${ }^{\mathrm{TM}}$ candles have a nominal pore size of $0.2 \mu$ and are impregnated with silver for bacteriostasis. According to the manufacturer, each candle can treat up to 50,000 liters of water depending on frequency of cleaning, and each candle can produce up to 1.5 liters/hour of filtered water depending on turbidity. Members of the intervention group attended a meeting during which they assembled their filter systems and received instructions on filling, using, and cleaning the system. They were encouraged to place the filter on a flat, stable surface that was accessible even to small children; to fill the unit as frequently as necessary using the same water that they pre- 
10

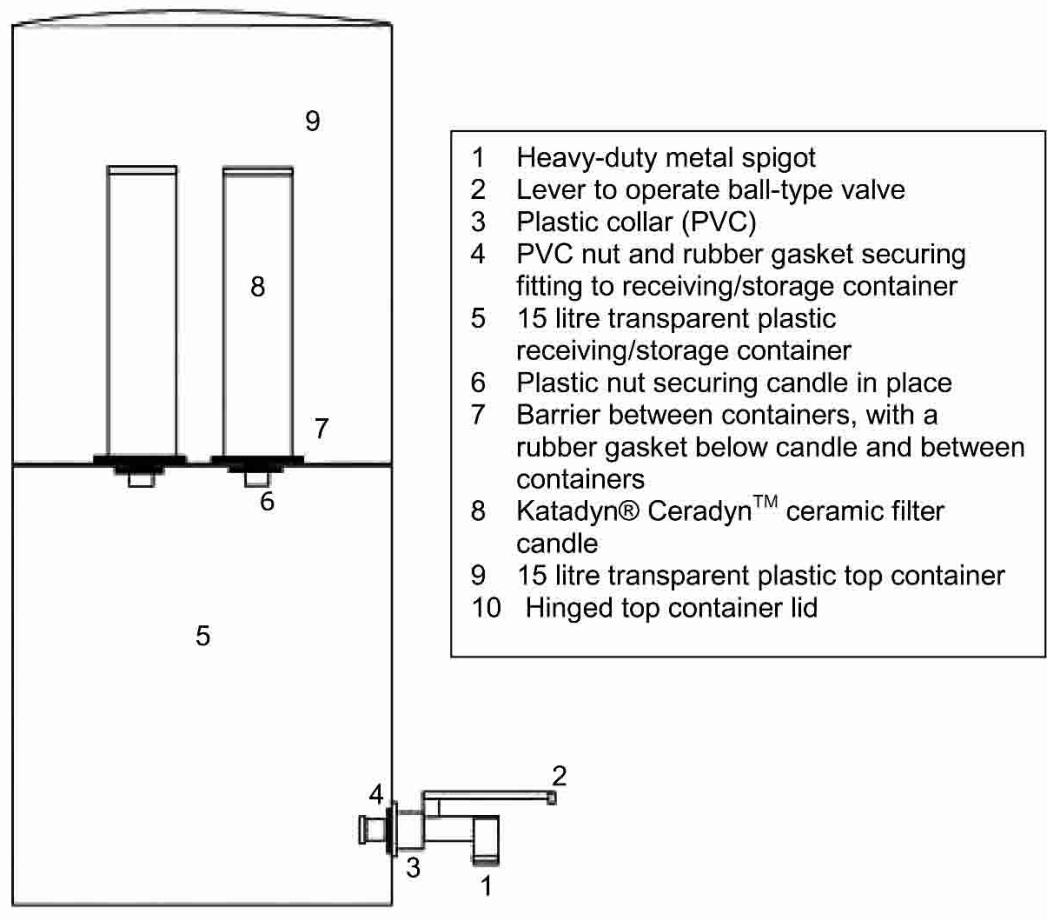

Schematic of filtration unit (not to scale).

FIGURE 1. Schematic of the ceramic filtration unit used in the field trial in Charinco, Bolivia.

viously used for drinking; to encourage all household members to use the filter for drinking, cooking, and cleaning eating utensils; and to clean the candles with a coarse sponge (also provided) whenever they noticed that the flow rate was reduced. They were also instructed to refrain from opening the lower vessel for any reason, and to access the filtered water solely from a cup or other utensil filled from the tap. Spare candles, buckets, and taps were left with the community leader. Two filter systems were also provided to the school master, one for each classroom. Apart from answering questions upon distribution of the system or in subsequent visits for sampling and diarrhea surveillance, no hygiene or other instructions, further training, or other explanations were provided as part of the intervention. Control households continued to use their customary practices for collecting, storing, and drawing drinking water. Placebo water filters were not issued to the control group for two reasons: 1) it would have been very difficult to devise a dummy water filter with identical filtration characteristics (improvement of clarity and palatability) but with no microbiologic effect, and 2) we were concerned at the ethical implication of control households changing their water consumption practices in the belief that water quality had been improved by a placebo filter.

Sampling and surveillance. Following the distribution of the filter systems in February 2003, an investigator returned to Charinco at approximately six-week intervals (weeks 7, 13, 19 , and 25) to record diarrhea prevalence during the previous seven days (defined as three or more loose stools during a period of 24 hours) and to obtain a sample of drinking water. Water was collected in sterile $125-\mathrm{mL}$ Nalgene ${ }^{\circledR}$ bottles (Nalge Nunc International, Rochester, NY). For the interven- tion group, water was sampled directly from the taps without flaming the tap so that the sample would reflect normal collection procedure and include any contamination associated with normal use. Water from the control group was collected from the vessel or reservoir used to fill a drinking cup. All samples were preserved between $4^{\circ} \mathrm{C}$ and $10^{\circ} \mathrm{C}$ and analyzed within four hours using the membrane filter technique. ${ }^{10} \mathrm{Be}-$ cause of anticipated levels of bacterial contamination, the analysis was performed on $100 \mathrm{~mL}$ of sample water from intervention households, but only $20 \mathrm{~mL}$ from the control households. Sample water was passed through a $0.45 \mu$ membrane filter (Millipore Corporation, Bedford, MA) and incubated on membrane lauryl sulfate media (Oxoid, Ltd., Basingstoke, Hampshire, United Kingdom) at $44 \pm 0.5^{\circ} \mathrm{C}$ for 18 hours in an Oxfam Delagua portable incubator (Robens Institute, University of Surrey, Gilford, Surrey, United Kingdom). The number of yellow colonies were counted (and multiplied by 5 in the case of the 20-mL samples) and recorded as individual thermotolerant coliforms (TTC). When a volume of $20 \mathrm{~mL}$ produced a number of yellow colonies that were too numerous to count, the count was assigned a value for purposes of statistical analysis of 3,000 TTC per $100 \mathrm{~mL}$.

Data collection and analysis. Data were recorded and analyzed using Epi-Info version 3.01 (Centers for Disease Control and Prevention, Atlanta, GA) with additional statistical analysis performed using Stata Release 7 (Stata Corporation, College Station, TX). Data from the control and intervention groups were compared by a two-sample $t$-test and by Fisher's exact test. Stepwise multivariate linear regressions were performed to determine possible associations between prevalence of diarrhea and baseline characteristics. Generalized 
estimating equations (GEEs) were used for the analysis of repeated observations of diarrhea in individuals over time and episodes of diarrhea in families controlling for clustering within households. Longitudinal prevalence of diarrhea was used as an outcome measure because of its association with diarrhea mortality. ${ }^{11}$

Ethics. Informed consent was obtained from the household head (usually, the senior male) at the beginning of the project. The project expectations and respective obligations by both the participants and investigators were explained and any questions were answered. The participants were not subjected to risks of any kind as a result of the project. The investigators provided feedback and information to the participants at regular intervals, conducting the project in the most open manner possible. The study was reviewed and approved by Ethics Committee of the London School of Hygiene and Tropical Medicine. All control group households received their filters on July 28, 2003. A plan for sustainable continuation of the project is currently being realized in association with Sumaj Huasi, the local non-governmental office.

\section{RESULTS}

Study participants and households. Baseline demographic and other characteristics for the control and intervention groups are shown in Table 1. A total of 50 households with 280 persons were recruited into the study (mean $=5.6$ persons per household) representing approximately $78 \%$ of the community's estimated population. The median age of the study population at the commencement of the study was 15 years (range $=1$ week to 86 years). Of the study participants $32(11 \%)$ were less than five years of age, and 148 (53\%) were female. Two people were lost to follow-up during the study (one adult from the control group and one child from the intervention group). Data on household construction and number of rooms were collected as proxies for economic status. Baseline data indicated statistically significant differences between intervention and control households in the number of occupants, use and observation of soap for hand washing, and dispensing of stored water by dipping or by pouring. Multivariate GEE analysis controlling for clustering within households did not show any correlation between these characteristics and prevalence of diarrhea.

Sanitation and hygiene practices. While two $(4 \%)$ of the households reported having latrines, in neither case was it used or usable. No other sanitation facilities were present. None of the heads of household reported that they had received any type of hygiene instruction during the six months immediately preceding the study. When asked about hand washing, 38 (76\%) of households reported using soap (normally washing powder for clothes), while the remainder reported using water only. Thirty-one $(62 \%)$ of the households could demonstrate to the investigator that soap was present in the household on the day of the interview.

Water handling practices. Apart from the rainy season (November to April) when four ( $8 \%$ ) of the study households reported occasionally harvesting rainwater, households in Charinco procure their water from open irrigation canals fed by a stream $(60 \%)$, directly from the stream itself $(21 \%)$, or from an unprotected hand-dug well. Most households have a small pond that they top off weekly when irrigation water is available. No household was more than 30 meters from the nearest canal (average $=9.2$ meters) or more than 200 meters from the stream. Water quantity is sufficient even in the dry season. The majority (65\%) of households used a barrel, bucket, clay pot, or tank for household water storage. Of 26 such containers, only 7 were covered. A jerry can was used for storage by $18 \%$ of the households. When asked to demonstrate how they would access the water for drinking, $85 \%$ of householders dipped a cup or other utensil into the stored water, while the balance poured from the container into a cup; none had a container with a tap or spigot from which they could access water. Two households reported occasionally treating their water before drinking, in both instances by boiling.

TABLE 1

Characteristics of intervention and control households*

\begin{tabular}{|c|c|c|c|}
\hline Characteristic & Intervention group & Control group & $P$ \\
\hline \multicolumn{4}{|l|}{ Demographic } \\
\hline$\geq 16$ years old & $59(47 \%)$ & $78(50 \%)$ & NS \\
\hline $5-15$ years old & $46(37 \%)$ & $54(35 \%)$ & NS \\
\hline$<5$ years old & $15(12.0 \%)$ & $17(11 \%)$ & NS \\
\hline Female & $66(53 \%)$ & $82(53 \%)$ & NS \\
\hline Total & 125 & 155 & - \\
\hline \multicolumn{4}{|l|}{ Household } \\
\hline Mean number of rooms & 2.56 & 2.80 & NS \\
\hline Mean number of occupants & 5.0 & 6.2 & 0.014 \\
\hline Adobe/brick construction & $15(60 \%) / 10(40 \%)$ & $17(68 \%) / 8(32 \%)$ & NS \\
\hline \multicolumn{4}{|l|}{ Sanitation and hygiene practices } \\
\hline Usable latrine & $0(0 \%)$ & $0(0 \%)$ & NS \\
\hline Normally wash hands with soap & $23(92 \%)$ & $15(60 \%)$ & 0.008 \\
\hline Soap observed in house & $17(94 \%)$ & $14(61 \%)$ & 0.014 \\
\hline \multicolumn{4}{|l|}{ Water handing practices } \\
\hline Draw water from canal, river, or rainwater & $17(68 \%), 2(8 \%), 2(8 \%)$ & $12(52 \%), 8(35 \%), 1(4 \%)$ & NS \\
\hline Normally transfer to a storage vessel & $15(60 \%)$ & $9(38 \%)$ & NS \\
\hline Storage vessel is covered & $5(24 \%)$ & $4(29 \%)$ & NS \\
\hline Storage vessel has tap & $0(0 \%)$ & $0(0 \%)$ & NS \\
\hline Draw drinking water by dipping, pouring & $23(96 \%), 1(4 \%)$ & $18(75 \%), 6(25 \%)$ & NS \\
\hline Boil or otherwise treat water before use & $1(4 \%)$ & $1(4 \%)$ & NS \\
\hline
\end{tabular}

\footnotetext{
* Demographic data are by individual; remaining data are by household. Number varies due to missing data. NS $=$ not significant (at the $5 \%$ level).
} 
TABLE 2

Arithmetic mean thermotolerant coliform (TTC) counts per $100 \mathrm{~mL}$ in drinking water samples from control and intervention groups*

\begin{tabular}{lcccccccc}
\hline & \multicolumn{3}{c}{ Intervention group } & & \multicolumn{3}{c}{ Control group } \\
\cline { 2 - 4 } \cline { 7 - 9 } & Observed & $\begin{array}{c}\text { TTC } \\
\text { count }\end{array}$ & $95 \%$ CI & & Observed & $\begin{array}{c}\text { TTC } \\
\text { count }\end{array}$ & $95 \%$ CI \\
\hline Baseline & 23 & 797 & $366-1,228$ & & 23 & 790 & $366-1,214$ \\
Week 7 & 23 & 0 & $0-0$ & & 24 & 705 & $231-1,180$ \\
Week 13 & 24 & 0 & $0-0$ & & 21 & 418 & $97-740$ \\
Week 19 & 25 & 0 & $0-0$ & & 24 & 173 & $28-319$ \\
Week 25 & 24 & 0 & $0-0$ & & 23 & 255 & $8-503$ \\
\hline
\end{tabular}

$* \mathrm{CI}=$ confidence interval.

Microbiologic impact. Prior to the introduction of the filters, the arithmetic mean TTC counts for the intervention and control groups were $797 \mathrm{TTC} / 100 \mathrm{~mL}$ and $790 \mathrm{TTC} / 100 \mathrm{~mL}$, respectively, a difference that was not statistically significant (Table 2). The range was $1-3,860 \mathrm{TTC} / 100 \mathrm{~mL}$ for the intervention group and $1-3,740 \mathrm{TTC} / 100 \mathrm{~mL}$ for the control group. Following introduction of the filters, $100 \%$ of the 96 samples from intervention households were free of TTC. Samples from the control group continued to have significant levels of TTC; $66 \%, 34 \%$, and $11 \%$ of the samples exceeded 10,100 , and $1000 \mathrm{TTC} / 100 \mathrm{~mL}$, respectively. Only $16 \%$ (15 of 96) control household samples tested meet the WHO standard of $0 \mathrm{TTC} / 100 \mathrm{~mL}$. The TTC counts in control households showed a statistically significant linear decrease with each visit over the duration of the study $(P<0.03)$.

Diarrhea reduction. Prior to the distribution of the filters the prevalence of diarrhea was similar in both the intervention and control groups (21.3\% versus $22.1 \%)$ and was within the range published by the Bolivian Ministry of Health. ${ }^{3}$ Diarrhea prevalence among the control group remained at this level (range $=18.8-23.1 \%$ ) during the entire six-month trial. The prevalence of diarrhea was significantly lower in the intervention group than in the control group (Figure 2). In the first round of diarrhea surveillance, the prevalence of diarrhea in the intervention group decreased by $77.2 \%$ from the baseline prevalence; in the control group, diarrheal prevalence increased by $2.7 \%$. The filter remained protective throughout the study. The GEE analysis showed a statistically significant difference in risk of diarrhea for individuals controlling for repeated episodes (estimated odds ratio [OR] = $0.30,95 \%$ confidence interval $[\mathrm{CI}]=0.20,0.47, P<0.001$ ) and for households controlling for clustering within households (estimated OR $=0.29,95 \% \mathrm{CI}=0.13,0.65, P=0.002$ ) between the intervention and control groups in the follow-up period. Risk of diarrhea for children less than five years old, controlled for clustering within households, was reduced by $83 \%$ (estimated OR $=0.17,95 \% \mathrm{CI}=0.06,0.49, P=0.001)$. The risk of diarrhea decreased by 0.97 (95\% CI $=0.96,0.99$, $P<0.02)$ for each year of life. The mean reduction in diarrhea prevalence during the six-month trial was $64 \%(P<0.0001)$. The reduction was highest among children less than five years old $5(72 \%)$ and lowest among adults (57\%) (Table 3). Prevalence of diarrhea in the intervention group showed a statistically significant upward trend over the course of the study $(P<0.02)$.

\section{DISCUSSION}

During a six-month intervention trial in rural Bolivia, household-based ceramic water filters eliminated all TTC

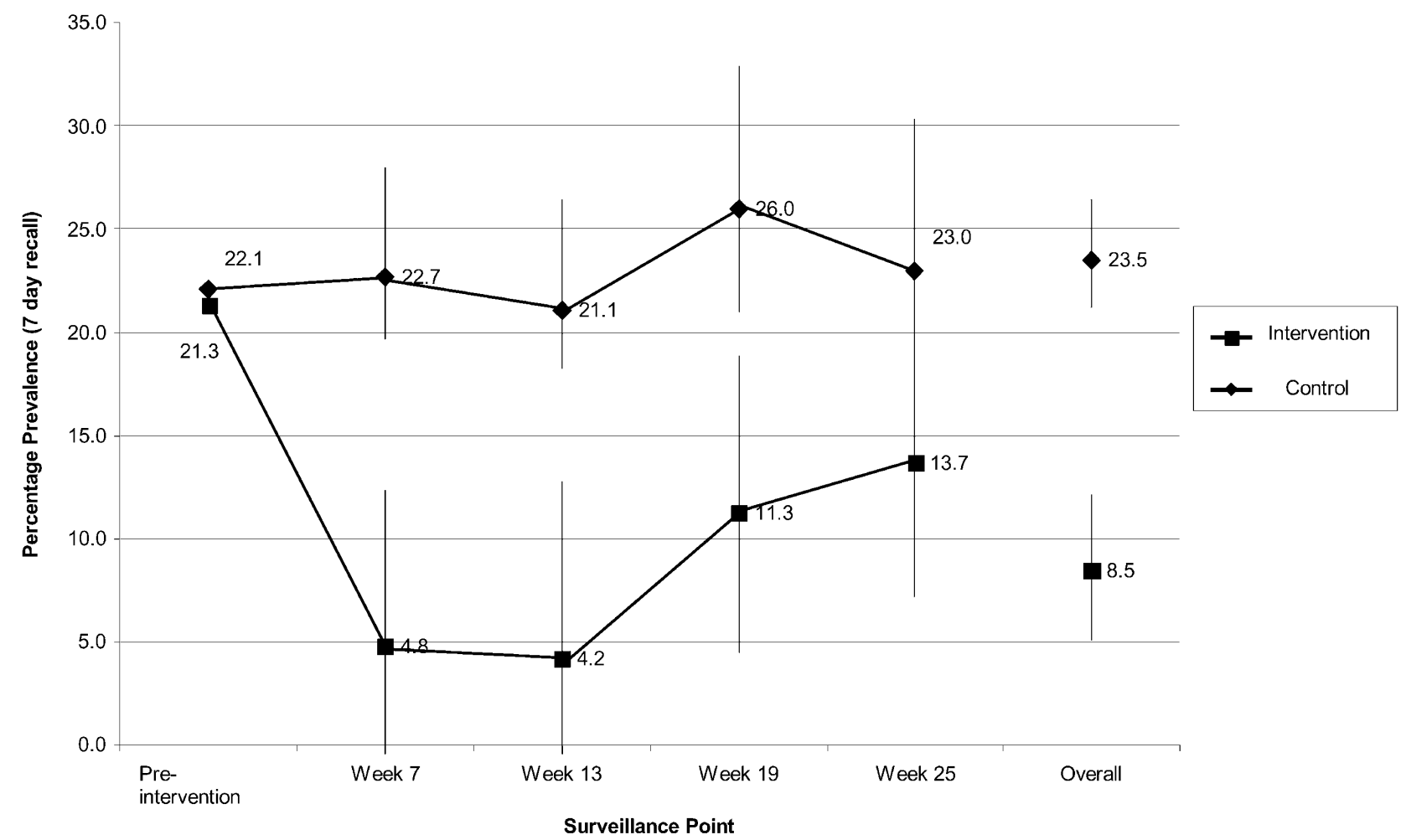

Figure 2. Diarrhea prevalence (points on the lines) and $95 \%$ confidence intervals (vertical bars) among control and intervention groups at baseline and at four rounds of surveillance. 
TABLE 3

Mean diarrhea prevalence by age among intervention and control groups*

\begin{tabular}{|c|c|c|c|c|}
\hline \multirow{2}{*}{$\begin{array}{c}\text { Age } \\
\text { (years) }\end{array}$} & \multicolumn{2}{|c|}{$\begin{array}{l}\text { Mean diarrhea prevalence } \\
\text { over six-month trial period }\end{array}$} & \multirow{2}{*}{$\begin{array}{l}\text { Reduction } \\
(95 \% \text { CI })\end{array}$} & \multirow{2}{*}{$\underset{(t \text {-test })}{P}$} \\
\hline & Intervention & Control & & \\
\hline$\geq 16$ & 0.064 & 0.149 & $57 \%(25,76)$ & $<0.002$ \\
\hline $5-15$ & 0.078 & 0.210 & $63 \%(35,79)$ & $<0.0004$ \\
\hline$<5$ & 0.165 & 0.578 & $72 \%(52,83)$ & $<0.0001$ \\
\hline Overall & 0.085 & 0.235 & $64 \%(50,74)$ & $<0.0001$ \\
\hline
\end{tabular}

from drinking water and were associated with a significant reduction in the prevalence of diarrhea. This study is believed to be the first in which a ceramic water filter was introduced as a health intervention for improving drinking water quality and reducing diarrhea among a vulnerable population. The results are particularly promising given the fact that the intervention was a simple and relatively inexpensive appliance (hardware) whose successful introduction did not need to be accompanied by motivational campaigns, extensive training, or other instruction (software). Such software has often been shown necessary to obtain health benefits with other household-based water interventions. ${ }^{12}$ This suggests that a significant health impact could potentially be achieved simply by distributing the device by commercial or other means that are more suitable to broad scale implementation, with minimal software compared with other interventions. Such software could, however, optimize the health benefits, reduce failures, and improve the longevity and sustainability of the intervention.

The principal methodologic weaknesses of this study are the use of a seven-day recall period and the lack of blinding or a placebo intervention. There is reason to believe that recall of episodes of diarrhea, particularly for family members other than oneself, is unreliable beyond 48 hours. ${ }^{13}$ The villagers may also have realized that the intervention was not unconnected with the diarrhea surveillance; control households could have exaggerated their disease rates so as to benefit from it in the future, or intervention households underreported them to please their benefactors. The consistency through time of the diarrhea rates reported by the control group, before and after the intervention (Figure 2), argues against such possibilities. There is, however, a statistically significant upward trend in the prevalence of diarrhea reported by intervention households. This trend could reflect a bias in reporting of diarrhea by intervention households; the bias might have been strongest at the start of the trial then decreased as the novelty wore off. Other factors contributing to this trend could have included increased consumption of unfiltered water by intervention households over the course of the study as a result of slower filtration rates or increased use of contaminated water from other sources as a result of water scarcity with onset of the dry season. The TTC counts in the control group decreased significantly over the course of the study, but the prevalence of diarrhea in the control group remained constant; this suggests that some other diarrheal pathogens or transmission routes contribute an increasing risk that may account for the upward trend in the prevalence of diarrhea reported by intervention households. Apart from devising a placebo water filter, these questions could be addressed by repeating our study over a period of 12 months or longer during which household water consumption practices would be monitored more closely.

In four successive rounds of water sampling, no TTCs were detected in the water produced by the filter system. While the Katadyn ${ }^{\circledR}$ ceramics used in the filter systems have demonstrated the capability of reducing fecal bacteria by more than $6 \operatorname{logs}$ in the laboratory ${ }^{14}$ and protozoa by $3 \operatorname{logs},{ }^{15}$ it was not clear whether such performance could be translated to the field or to a population that did not receive hygiene instruction or other training. The absence of detectable TTC is similar to the results obtained in trials involving other householdbased water treatment interventions including chlorination, ${ }^{16,17}$ solar disinfection, ${ }^{18}$ and combined flocculation/ disinfection. ${ }^{19}$ The fact that the filters can eliminate these fecal bacteria without a requirement for chemicals (which could discourage use by some consumers) presents an advantage over interventions that rely on chemical disinfection. Moreover, unlike household-based chlorination and solar disinfection, the units perform well in moderate and variable turbidity and regardless of temperature or level of $\mathrm{pH}$.

Recontamination of coliform-free water is also a major risk, particularly when the product water is not protected by residual disinfectant. ${ }^{20}$ Studies have shown, however, that an improved vessel can improve water quality and reduce diarrhea even in the absence of residual chlorine simply by reducing contact with contaminated hands. ${ }^{21}$ The lack of TTC in filtered water suggests that the system has overcome the risk of recontamination. This is probably due to the design of the unit, which does not permit contaminated water, hands, fomites, or mechanical vectors to come into contact with the product water. Key design features of the filter system include 1) the tight-fitting lid over the reservoir vessel, 2) the fact that the candles can be cleaned without opening this reservoir, 3) a tight seal between the candles and the lower reservoir that prevents water from entering during filling, and 4) the tap that allows access to the treated water without coming into contact with hands or utensils.

The filter system was also associated with a significant reduction in the prevalence of diarrhea among the intervention households. There were statistically significant $(P<0.05)$ differences in baseline data between the control and intervention groups for mean number of (adult) occupants, use and observation of soap for hand washing and means of accessing water from household storage vessel. However, multivariate GEE analysis controlling for clustering within households did not show any consistent association between these or any other baseline characteristics and prevalence of diarrhea. The $70 \%$ reduction in diarrhea prevalence is substantially higher than the $15-17 \%$ predicted in previous reviews of interventions that only improve water quality. ${ }^{22,23}$ This result is particularly interesting in view of what has become the dominant paradigm in water and sanitation interventions: that to achieve broad health impact, greater attention should be given to safe excreta disposal and proper use of water for personal and domestic hygiene rather than to drinking-water quality. ${ }^{24}$ It is also inconsistent with studies that conclude that an improvement in drinking water quality does not translate into reduced diarrhea unless there is a previous or concomitant improvement in sanitation. ${ }^{24}$

The reduction in the prevalence of diarrhea associated with the intervention is not, however, inconsistent with the growing number of trials involving improved household-based wa- 
ter management, whether accompanied by other water and sanitation interventions. ${ }^{25-33}$ A summary of 21 such studies concluded that the median reduction in diarrhea morbidity associated with improved household water treatment and storage was $42 \%$ (range $=0-88 \%) .{ }^{34}$ While the results from Charinco are within this range, higher percentage reduction may be attributable to several factors, including the use of prevalence as an outcome measure (rather than incidence, the measure used in most other studies), the nature of the intervention (combining treatment and safe storage), the ambient water quality, and the hygiene or sanitation practices of the community. A Cochrane Review of these and other trials involving improvements in water quality that specifically examines differences in the nature of the interventions, the study site, and the study methodology is presently underway. ${ }^{35}$ This may show that improved treatment and storage of water at the household level represents a refinement to the dominant paradigm. ${ }^{36}$

The higher reduction in diarrhea associated with the filter could also be attributed to its acceptability and favorable perception among users (Brown J, unpublished data). All of the 24 intervention households interviewed reported that they liked the filter, and $96 \%$ of respondents would recommend it to others; $92 \%$ reported that they did not find using the filter inconvenient, $71 \%$ said that using the filter did not add significantly to their household duties, and $92 \%$ reported that since using the filter they felt better. At the same time, in only $72 \%$ of the cases were the filters clearly in use at the time water was sampled, and the same percentage acknowledged that they at least occasionally drank unfiltered water either while away (40\%), while working (27\%), or when the filter was empty or slow $(27 \%)$. Almost half $(46 \%)$ reported that the filter was occasionally too slow to provide water for the family at all times. Eight of the 25 filters were broken or temporarily out of service during the course of the project, a significant failure rate that could perhaps be reduced by improved design and instruction. This suggests that although significant health gains were observed with minimal software, additional support and education could be effective in increasing sustainability of the intervention.

Contingent valuation methods were used to assess willingness-to-pay for the intervention (Brown J, unpublished data). When asked to estimate the cost of the filter, the mean response was equivalent to U.S. \$24.18. However, when asked the maximum they would pay for the filter, the mean response was equivalent to U.S. \$9.25. Seventy-seven percent said they would pay 50 Bolivianos (approximately U.S. \$7), but only $32 \%$ would pay 100 Bolivianos (U.S. \$13.50) and $16 \% 150$ Bolivianos (U.S. \$20). The cost of the vessels, valves, and fabrication (drilling holes) is approximately U.S. $\$ 7.50$, the balance being the cost of the candles. The actual total cost of the filter system used in Charinco was approximately U.S. $\$ 25$. This is remarkably close to householders' estimates, but still well above the amount that most study participants reported that they were willing to pay. Assuming daily usage of 25 liters/system, the total operating cost of the system is approximately U.S. $\$ 0.006$ per household per day, or U.S. $\$ 0.00025$ per liter. Ceramics compare favorably with other interventions, including chlorination and boiling, when both up-front and recurrent costs are considered. ${ }^{8}$ Cost savings could be realized by reducing the size of the candle or using a single candle. There may be other options, such as payment in installments, to improve the up-front affordability of the system and thereby improve the opportunity to distribute the unit commercially without governmental subsidies. While data on willingness to pay should not be generalized beyond the economic conditions under which it was collected, since Bolivia is one of the poorest countries in Latin America, these results suggest that a significant proportion of vulnerable populations may be able to afford a ceramic water filter system.

Apart from dealing with the initial cost, the major question about the use of ceramic microfiltration for treating water relates to their ability to remove waterborne viruses. Ranging in size from 20 to $100 \mathrm{~nm}$, viruses are too small by themselves to be eliminated by microfiltration. There is some evidence that viral particles tend to aggregate or associate with bacteria and other larger particles. ${ }^{37}$ As a result, filters have been shown to be capable of reducing waterborne viruses at a rate that is greater than might be expected based on the size of the microbe. ${ }^{8}$ There is ambiguous epidemiologic evidence about the protective effect of household ceramic filters against hepatitis A virus. ${ }^{38}$ Further testing is necessary to determine the level, if any, of such removal, as well as the extent to which chemical coatings or other enhancements to the filter media could result in sufficient virus removal or deactivation to protect communities from waterborne viral pathogens. ${ }^{39}$

The results from this trial suggest that household-based ceramic gravity water filters may be an effective intervention in improving microbial water quality and reducing diarrheal disease among a susceptible population. In this respect, ceramic filtration may be another useful tool in helping the most vulnerable populations secure the health benefits of safe drinking water. Additional trials are under way to explore such effectiveness in other settings and to address some of the shortcomings of this method.

Received December 8, 2003. Accepted for publication February 23, 2004.

Acknowledgments: We express our gratitude to the community of Charinco for participating in this study. We are also grateful to Linda Venczel and Diego Daza (Pan American Health Organization, La Paz, Bolivia); Simon Cousens (London School of Hygiene and Tropical Medicine); and Eric Mintz, Rob Quick, and Jon Macy (Centers for Disease Control and Prevention, Atlanta, GA) for their assistance with this study.

Financial support: This study was supported by First Water, Ltd., The Gates Cambridge Trust, and Trinity Hall, University of Cambridge, United Kingdom.

Disclosure: Thomas F. Clasen is president and an employee of First Water, Ltd., which designs, evaluates, and sells point-of-use water treatment products, including ceramic filters. Simon Collin is paid by First Water, Ltd. to develop and supply household water treatment products, including ceramic filters. These statements are made in the interest of full disclosure and not because the authors consider this to be a conflict of interest.

Authors' addresses: Thomas F. Clasen and Sandy Cairncross, Disease Control and Vector Biology Unit, Department of Infectious and Tropical Diseases, London School of Hygiene and Tropical Medicine, Keppel Street, London, WC1E 7HT, United Kingdom, Telephone: 44-20-7636-8636, Fax: 44-20-7436-5389, E-mails: thomas.clasen@ lshtm.ac.uk and sandy.cairncross@lshtm.ac.uk. Joseph Brown, Department of Environmental Sciences and Engineering, University of North Carolina, Rosenau Hall, CB\# 7431 Chapel Hill, NC 275997431, Telephone: 919-966-2488, Fax: 919-966-7911, E-mail: joebrown@email.unc.edu. Simon Collin, First Water, Unit 62, Spike Island, 133 Cumberland Road, Bristol, BS1 6UX, United Kingdom, Telephone: 44-117-922-5950, Fax: 44-117-929-2066, E-mail: simon@ firstwater.info. 


\section{REFERENCES}

1. Kosek M, Bern C, Guerrant RL, 2003. The global burden of diarrhoeal disease, as estimated from studies published between 1992 and 2000. Bull World Health Organ 81: 197-204.

2. Parashar UD, Bresee JS, Glass RI, 2003. The global burden of diarrhoeal disease in children (editorial). Bull World Health Organ 81: 236.

3. Ministry of Health, Bolivia, 2003. Salud del Niño. Available at www.sns.gov.bo/salnin.html.

4. Guerrant DI, Moore SR, Lima AA, Patrick P, Schorling JB, Guerrant RL, 1999. Association of early childhood diarrhoea and cryptosporidiosis with impaired physical fitness and cognitive function four-seven years later in a poor urban community in northeast Brazil. Am J Trop Med Hyg 61: 707-713.

5. Baqui AH, Black RE, Sack RB, Chowdhury HR, Yunus M, Siddique AK, 1993. Malnutrition, cell-mediated immune deficiency and diarrhea: a community-based longitudinal study in rural Bangladeshi children. Am J Epidemiol 137: 355-365.

6. Schneider RE, Shiffman M, Faigenblum J, 1978. The potential effect of water on gastrointestinal infections prevalent in developing countries. Am J Clin Nutr 31: 2089-2099.

7. WHO/UNICEF, 2000. Global Water Supply and Sanitation Assessment. Geneva: World Health Organization. Available at http://www.wssinfo.org/en/pdf.

8. Sobsey MD, 2002. Managing Water in the Home: Accelerated Health Gains from Improved Water Supply. Geneva: World Health Organization (WHO/SDE/WSH/02.07). Available at http://www.who.int/water_sanitation_health/dwq/wsh0207/en/.

9. Clasen T, Bastable A, 2003. Faecal contamination of drinking water during collection and household storage: the need to extend protection to the point of use. J Water Health 1: 109115.

10. Ciesceri LS, Greenberg AE, Eaton AD, eds, 1998. Standard Methods for Examination of Water and Wastewater. 20th edition. Washington, DC: American Public Health Association.

11. Morris SS, Cousens SN, Kirkwood BR, Arthur P, Ross DA, 1996. Is prevalence of diarrhea a better predictor of subsequent mortality and weight gain than diarrhea incidence? Am J Epidemiol 144: 582-588.

12. Thevos A, Olsen S, Rangel J, Kaona F, Tembo M, Quick R, 2003. Social mrketing and motivational interviewing as community interventions for safe water behaviors: follow-up surveys in Zambia. Int Q Community Health Education 21: 51-65.

13. Boerma JT, Black RE, Sommerfelt AE, Rutstein SO, Bicego GT, 1991. Accuracy and completeness of mothers' recall of diarrhoea occurrence in pre-school children in demographic and health surveys. Int J Epidemiol 20: 1073-1080.

14. Hörman A, 2003. Evaluation of the purification capacity of nine portable, small scale water purification devices. Proceedings of the International Water Association/WHO International Symposium on Health-Related Water Microbiology. Cape Town, South Africa, September 14-19, 2003.

15. Ongerth JE, Johnson RL, Macdonals SC, Frost F, Stibbs HH, 1989. Backcountry water treatment to prevent giardiasis. Am J Public Health 79: 1633-1637.

16. Quick R, Venczel L, Gonzalez O, Mintz E, Highsmith A, Espada A, Damiani E, Bean N, de Hannover R, Tauxe R, 1996. Narrow-mouthed water storage vessels and in situ chlorination in a Bolivian community: a simple method to improve drinking water quality. Am J Trop Med Hyg. 54: 511-516.

17. Luby S, Agboatwalla M, Raza A, Sobel J, 2001. A low-cost intervention for cleaner drinking water in Karachi, Pakistan. Int $J$ Infect Dis 5: 144-150.

18. McGuigan KG, Joyce TM, Conroy RM, Gillespie JB, ElmoreMeegan M, 1998. Solar disinfection of drinking water contained in transparent plastic bottles: characterizing the bacterial inactivation process. J Appl Microbiol 84: 1138-1148.

19. Rangel J, Lopez B, Alvarez MM, Mendoza C, Luby S, 2003. A novel techonolgy to improve drinking water quality: a microbiological evaluation of in-home flocculation and chlorination in rural Guatemala. $J$ Water Health 1: 15-22.

20. Wright J, Gundry S, Conroy R, 2003. Household drinking water in developing countries: a systematic review of microbiological contamination between source and point-of-use. Trop Med Int Health 9: 106-117.

21. Roberts L, Chartier Y, Chartier O, Malenga G, Toole M, Rodka $\mathrm{H}, 2001$. Keeping clean water clean in a Malawi refugee camp: a randomized intervention trial. Bull World Health Organ 79: 280-287.

22. Esrey SA, Feachem RG, Hughes JM, 1985. Interventions for the control of diarrhoeal diseases among young children: improving water supplies and excreta disposal facilities. Bull World Health Organ 64: 776-782.

23. Esrey SA, Potash JB, Roberts L, Shiff C, 1991. Effects of improved water supply and sanitation on ascariasis, diarrhoea, dracunculiasis, hookworm infection, schistosomiasis, and tracoma. Bull World Health Organ 69: 609-621.

24. Esrey SA, Habicht J-P, 1986. Epidemiologic evidence for health benefits from improved water and sanitation in developing countries. Epidemiol Rev 8: 117-128.

25. Sobsey MD, Handzel T, Venczel L, 2003. Chlorination and safe storage of household drinking water in developing countries to reduce waterborne disease. Water Sci Technol 47: 221-228.

26. Reller ME, Mendoza CE, Lopez MB, Alvarez M, Hoekstra RM, Olson CA, Baier KG, Keswick BH, Luby SP, 2002. A randomized controlled trial of household-based flocculant-disinfectant drinking water treatment for diarrhea prevention in rural Guatemala. Am J Trop Med Hyg 64: 411-419.

27. Quick RE, Kimura A, Thevos A, Tembo M, Shamputa I, Hutwagner L, Mintz E, 2002. Diarrhea prevention through household-level water disinfection and safe storage in Zambia. $A m J$ Trop Med Hyg 66: 584-589.

28. Conroy RM, Meegan ME, Joyce T, McGuigan K, Barnes J, 1999. Solar disinfection of water reduces diarrhoeal disease: an update. Arch Dis Child 81: 337-338.

29. Iijima Y, Karama M, Oundo JO, Honda T, 2001. Prevention of bacterial diarrhea by pasteurization of drinking water in Kenya. Microbiol. Immunol. 45: 413-416.

30. Quick RE, Venczel LV, Mintz ED, Soleto L, Aparicio J, Gironaz M, Hutwagner L, Greene K, Bopp C, Maloney K, Chavez D, Sobsey M, Tauxe RV, 1999. Diarrhoea prevention in Bolivia through point-of-use water treatment and safe storage: a promising new strategy. Epidemiol Infect 122: 83-90.

31. Semenza JC, Roberts L, Henderson A, Bogan J, Rubin CH, 1998. Water distribution system and diarrheal disease transmission: a case study in Uzbekistan. Am J Trop Med Hyg 59: 941-946.

32. Mahfouz A, Abdel-Moneim M, Al-Erian R, Al-Mari O, 1995. Impact of chlorination of water in domestic storage tanks on childhood diarrhoea: a community trial in the rural areas of Saudi Arabia. J Trop Med Hyg 98: 126-130.

33. Deb BC, Sircar BK, Sengupta PG, De SP, Mondal SK, Gupta DN, Daha NC, Ghosh S, Mitra U, Pal SC, 1986. Studies on interventions to prevent El Tor cholera transmission in uran slums. Bull World Health Organ 64: 127-131.

34. Clasen T, 2003. Disease reduction through household water treatment. Proceedings of the International Water Association/ WHO International Symposium on Health-Related Water Microbiology. Cape Town, South Africa, September 14-19, 2003.

35. Clasen T, Roberts I, Rabie T, Cairncross S, 2004. Interventions to improve water quality for preventing infectious diarrhoea (Protocol for a Cochrane Review). The Cochrane Library, Issue 2, 2004

36. Clasen T, Cairncross S, 2004. Household water treatment: refining the dominant paradigm. Trop Med Intl Health 9: 187-191.

37. Melnick JL, Gerba CP, Wallis C, 1978. Viruses in water. Bull World Health Organ 56: 499-508.

38. Almeida LM, Werneck GL, Cairncross S, Coeli CM, Costa MC, Coletty PE, 2001. The epidemiology of hepatitis A in Rio de Janeiro: environmental and domestic risk factors. Epidemiol Infect 127: 327-333.

39. Scott TM, Sabo RC, Lukasik J, Boice C, Shaw K, ArrosoGiachetti L, El-Shall H, Farrah SR, Park C, Moudgil B, Koopman B, 2002. Performance and cost-effectiveness of ferric and aluminium hydrous metal oxide coating on filter media to enhance virus removal. KONA 20: 159-167. 